\title{
GOVERNANCE ASSESSMENT AND IMPROVEMENT TOOL FOR PUBLIC ORGANIZATIONS IN JORDAN
}

\author{
Hasan Mansur', Anita Tangl ${ }^{2}$ \\ ${ }^{I}$ PhD Candidate, Doctoral School of Management and Business Administration, SzentIstvan University, Godollo, \\ Hungary \\ ${ }^{2}$ Associate Professor, Faculty of Economics and Social Science, SzentIstvan University, Godollo, Hungary
}

\begin{abstract}
The purpose of this research is to discuss good governance in public organizations in Jordan; it highlighted the theoretical basis of governance assessment, explained each of nine governance principles, and explained how the good governance should be reflected on the governmental financial reporting. This research is a descriptive based on analysis of governance assessment as an improvement tool in Jordan; it takes into consideration only public organizations and the accountable governance in public organizations. The most important findings were that governance assessment tool aims to motivate public organizations to engage in a continuous improvement of good governance path, allowing them to identify strengths and weakness and to benchmark with best practices. Moreover, Professional public accountants in public organizations have a responsibility to provide objective and accurate information and analyses to support planning, implementing, executing, evaluating, and improving governance, as well as overall responsibility in governance areas. These factors put professional accountants in an excellent position to ensure that governance is integrated throughout an organization.
\end{abstract}

Keywords: - Good governance, Governance Assessment, Accountable Governance in public organizations

\section{INTRODUCTION}

The Hashemite Kingdom of Jordan Governance Assessment and Improvement Tool (GAIT) aims to help public organizations to improve and assess their governance practices. Good governance is a complex and multidimensional concept[1]; it involves pursuing a set of principles throughout the whole policy cycle of an organization. Therefore, Good governance is more a path, a way of developing public activities, than a single characteristic of a public organization. GAIT attempts to conceptualize and explain the necessary conditions for pursuing good governance, providing examples and evaluation questions, which may help public authorities, civil servants and external evaluators to engage in a continuous improvement path [1].

GAIT is a micro-level model, as it provides a framework of analysis of governance for single public organization[2].

GAIT aims to be complementary to managerial tools for improving quality of public organizations, efficiency, effectiveness or citizen/customer satisfaction (like Total Quality Management models, Strategic Planning, Balance Scorecards, Service Charters, Citizen Surveys, etc.). In fact, public organizations that already used any of these managerial tools will find that GAIT rewards its use. In respect to these management tools, GAIT acts as an umbrella, providing a common framework to organize how the use of these management tools may improve good governance in the organization [3].
Currently, a large number of stakeholders including governments, regulators, oversight bodies, standard setters, and professional bodies, as well as international agencies and organizations, such as the International Organization of Securities Commissions, Organization for Economic Cooperation and Development, United Nations Conference on Trade and Development, and World Bank are debating governance challenges and solutions. Together, these organizations will have a significant impact on determining the necessary and feasible changes for organizations and economies [4].

The accountancy profession including professional accountants, professional accountancy organizations, and IFAC is also urging that organizations around the globe evaluate and improve their governance arrangements in order to achieve more sustainable social, environmental, and economic performance [4].

GAIT itself (as most recognized self-assessment models like European Foundation Quality Management (EFQM) or Common Assessment Framework (CAF) [5] is also engaged in a continuous improvement path. Therefore, Ministry of public sector development (MoPSD) will publish successive versions of GAIT in order to adapt to future developments in public organizations and social changes, including new examples of good practices and evaluation questions.[1]. 


\section{RESEARCH PROBLEM}

Paragraph comes content here.Paragraph comes content here.Paragraph comes content here. Paragraph comes content here.Paragraph comes content here.Paragraph comes content here. Paragraph comes content here.Paragraph comes content here.Paragraph comes content here. Paragraph comes content here.Paragraph comes content here.Paragraph comes content here.

\section{RESEARCH OBJECTIVE}

The main purpose of this research is to discuss Good governance in public organizations in Jordan; it highlights the theoretical basis of governance assessment, explained each of nine governance principles, and explained how the good governance should be reflected on the governmental financial reporting

\section{RESEARCH DESIGN/METHEDOLOGY}

This research will overview and analyze the literatures that dealt with governance in public sector, analyze the related models and highlights on the principles and dimensions that should be used in the application of governance assessment as an improvement tool in Jordan.

\section{LITERATURE REVIEW}

\subsection{Using of Governance Assessment and}

\section{Improvement Tool (GAIT)}

Good Governance is a qualitative, multidimensional and complex concept. Therefore, it is neither directly quantifiable nor directly observable. Internal and external evaluators need to gather and observe carefully all evidences about the public organization functioning[1].

GAIT provides internal and external evaluators with a logical framework to assess governance. For doing so, it contains a set of examples and evaluation questions which operationalize the different good governance criteria regarding to each dimension of the public organization [6].

These operationalization and questions should be used as a guide for reflecting on the organization. This means that public authorities, civil servants and external evaluators using GAIT should depart from superficial and mechanical (yes/no) answers and conclusions. Indeed, they should involve in a deep analysis of evidence and an in-depth qualitative assessment of what should be done to improve good governance in the organization [7].

As public organization may be very different in size, political capacities, powers, functions tasks and responsibilities, GAIT is a general tool, giving general guidelines on evidences and evaluation questions. It is possible and desirable that internal and external evaluators using GAIT customize the evaluation questions and the evidences to the nature of the public organization being assessed. It also might be possible to develop in the future some sectorial versions of GAIT (e.g., GAIT for Education, GAIT for citizen/customer service offices), which may include concrete sectorial examples and necessary evidences[8].

GAIT is structured in 9 good governance principles and 12 dimensions of public organizations. The 9 principles: Rule of Law, Transparency, Accountability, Participation, Integrity, Equity, Effectiveness, Efficiency and Sustainability). These principles are the most accepted principles in the international literature on good governance and good administration [7].

The 12 dimensions cover the whole activity and policy cycle of a public organization: basic structure (Legislation and Basic Regulation, Organizational Structure); inputs used by the organization (Leadership, Strategy and Planning, Human Resources, Financial Resources, Alliances \& Other Resources); its activities (Processes); and its results, including internal results (Human Resources results and Financial \& Alliance Results), outputs (Outputs and User results) and outcomes (Impact in society) [7].

This structure implies that each dimension of the public organization should be evaluated according to the different good governance principles. It implies operationalizing each one of the principles referring to a concrete dimension[9].

This matrix design may allow public organizations to engage either in a complete systematic assessment of their governance, or to take a first partial approach. The partial approach may be horizontal (e.g. assessing transparency in all the 12 dimensions), or vertical (assessing the 9 principles -e.g. Rule of Law, Integrity, etc. - regarding to only one dimension -e.g. Human Resources Management) [10].

Even though a systematic complete approach may be preferable, some organizations may consider useful to start with a partial horizontal or vertical approach, which will be less costly in terms of resources and time, yet useful to start a continuous improvement path, detecting strengths and weaknesses, through the scoring process and even get validation of their scoring and their improvement plans by the MoPSD [11].

\subsection{Differences and Similarities with Other Models}

Evaluating good governance is a very complex matter. Most standards, indicators and evaluation reports are conducted at a macro level (the whole public sector of a country). For example "The Principles of Public Administration: A Framework for European Neighborhood Policy (ENP) Partner Countries" are oriented to assess the core horizontal elements of the public administration in a holistic view [9].

There are only few tools that aim to evaluate governance at a micro level. Perhaps, the most widely known is International Framework: Good Governance in the Public 
Sector, launched in 2014 by the International Federation of Accountants (IFAC). However, this tool focuses on providing guidance and reporting (inspired by integrated reporting movement in the private sector), and it does not include any quantitative scoring mechanism [12]. Similarly, most national governance tools consist on a set of principles and guidelines for act and reporting mechanisms (sometimes including check-lists). Very few of them include scoring, and the ones who do often claim that "the ratings provide agencies with a benchmark but should not be used as a comparison tool across agencies" [11].

GAIT synthetic good-governance indicator does not aim to be an exact measure of good governance; neither it aims to provide a reliable measure to compare between agencies. It only aims to incentive public organizations to engage in a continuous improvement of good governance path, allowing them to identify strengths and weakness and to benchmark with best practices [10].

\subsection{Governance}

Governance in the public sector may be defined as the host of legislation, organizational structures, policies, procedures and controls that govern the manner in which a government organization functions [13].

The ultimate objective of governance is to create and optimize sustainable organizational success and stakeholder value, balancing the interests of the various stakeholders. It comprises arrangements put in place to ensure that organizations define and achieve intended outcomes [4].

In brief, governance is the set of arrangements undertaken by a government department to guarantee the achievement of its goals [14].

\subsubsection{GAIT's 12 Evaluation Dimensions}

In order to evaluate governance, it is necessary to decompose a public organization functioning in several dimensions, according to a logical model. The GAIT uses a logical model based on the modern approach of public program evaluation and Total Quality Management, which covers the whole policy-cycle of a public organization.

Leaders, according to approved strategies, manage the way the public organization uses its resources (human resources, financial resources, material and intellectual resources, contracts and alliances) and performs its activities (through processes). Activities in public organizations mainly consist on the provision or production of public services, regulatory activities, or supervisory and disciplinary procedures (outputs) [10]

Of course, there are external political and socioeconomic conditions that influence not only the impact of a publicorganization, but also its resources and its capacities. These impacts also influence public opinion and civil society, which also influence the way the public organizations behave and even organize, in a continuous feedback process [7].

Dimensions 1 to 8 (legislation, organizational structure, leadership, strategies, resources and processes) are usually call enablers. They refer to what the organization does to fulfill its mission. Dimensions 9 to 11 are usually called results or outputs. Dimension 12 is usually called impacts or outcomes.

\subsubsection{GAIT's 9 Principles of Good Governance}

Governance, as defined in the previous section, is a positive concept. It defines how a public organization functions (e.g. how it is organized, what are its decision-making processes, what are their policies and strategies, how it manages its resources, how it produces its services and what results it achieves).

Good governance is a normative concept. Distinguishing good and bad governance practices requires settling some normative principles and criteria based on values. As the United Nations Office of the High Commissioner for Human Rights of the (OHCHR) points out "there is no single and exhaustive definition of "good governance," nor is there a delimitation of its scope, that commands universal acceptance" [6].

According to the above, GAIT includes the following 9 principles:

\subsubsection{Rule of Law}

Rule of Law requires that all procedures, actions and decisions of public organizations respect the relevant legislation, which is applied and enforced. It also requires that actions and procedures of public organizations are reliable and predictable (legal certainty) [10].

At a micro level (for a single public organization), the rule of law has two dimensions. First, the public organization should apply all relevant higher laws and regulations in a consistent manner and according to a fair, not self-interested interpretation. Public organizations should not interpret laws to their benefit. In case of legal loopholes, indefinite legal concepts or competing interpretations, public organizations should formulate questions to the competent authorities if possible. Thus, public organizations' decisions should be based on the applicable external laws and internal rules, according to an objective, non-biased, consistent and predictable interpretation. Decisions should be motivated and never arbitrary [10].

\subsubsection{Transparency}

Good Governance requires that public regulations, activities, decisions, etc. are transparent. This means that they might be published or provided to the applicant in a reasonable time after the he asks for this information. The informationthat might be disclosure depends on 
classification of the information, according to the Hashemite Kingdom of Jordan Law on access to information No. 47 of the year 2007. In order to pursue transparency, information published or provided should be clear, complete, relevant and understandable by stakeholders. [11].

It is important to point out that the Hashemite Kingdom of Jordan is the first country in the Arab World to adopt legislation that guarantee the right to access to information. However, even though enacting a right to access to information law is a big step forward, good governance at micro-level requires setting the right institutional mechanisms and procedures inside the organizations to ensure that transparency is implemented in practice [10].

For example, it is necessary to adopt some rules and regulations about internal registries and databases. It is not possible to disclose timely and clearly information that is not stored adequately. Equally, it has proven useful the appointment of a centralized internal unit, which receives, processes and answers petitions of information. It has also proven useful designating people in each department (e.g. public procurement, finance) responsible to give information to this centralized internal unit. Of course, adequate training in the right to access to information is needed, as well as training on how to provide clear and complete information [6].

\subsubsection{Accountability}

Good governance requires that public organizations, public authorities and civil servants are accountable for their actions and decisions. This means that public organizations, public authorities and civil servants (the accountors) have the obligation to inform, explain and justify their conducts to a forum (the accountee), and this forum has the possibility of inquiring questions, debating and evaluating the actions of the accountor. Accountability in this narrow definition also requires that the accountors might be subject to a reaction or a response, as a consequence of the evaluation derived from the accountability exercise [15].

The most basic form of accountability is the vertical accountability. This is the process in which any public organization is accountable to its hierarchical superior. In this case, the response derived the accountability exercise may be a formal action (e.g. removal of the director general of the organization or administrative sanctions) in case of illegal behavior or severe misadministration of the organization [15].

Governance encourages better organizational decision making and accountability for the efficient stewardship of resources. It is also characterized by robust scrutiny, which provides important pressure for improving organizational performance [4].

\subsubsection{Participation}

Participation, or it is sometimes called, participatory governance, requires allowing stakeholders to play an active role in the decision making, implementation, monitoring and evaluation of public policies. This is a broad interpretation of participation, as it implies that citizens and stakeholders can participate in all phases of the public policy cycle. In fact, participation transforms policy decision in co-decision, design in co-design, production in co-production and evaluation in co-evaluation. [16].

\subsubsection{Integrity and Prevalence of Morals}

Integrity is defined as dealing with everybody with justice, avoiding any form of discrimination or bias, acting with professionalism and objectivity, recognizing and respecting others' rights, not surrendering to the temptations of illegal or unjust benefit, and not misusing information or resources [17].

There is not a single mechanism that ensures to achieve a perfectly ethical behavior of all public authorities and civil servants. However, there are several institutional frameworks that disincentive or difficult integrity and unequal behaviors. Thus, good governance requires public organizations to engage in developing policies and institutional frameworks to eradicate favoritism, nepotism, wasta and any kind of corruption. These institutional agreements include code of conducts, proportional disciplinary sanctions for breaching integrity provisions with a fair procedure, training, ethic advisory councils which might solve integrity issues raised by employees, safe mechanisms for citizens and public employees to report wrong behavior of public authorities and public officials [8].

\subsubsection{Equity}

Equity consists in the capacity of public organizations to deliver public services and achieve their goals (social impact) according to social justice. This means counting on objective rules and procedures aiming to promote equal opportunities and results for citizens. "The Principles of Public Administration: A Framework for ENP Partner Countries" recognize the important of equity in public service provision [18].

Good governance requires public organizations to evaluate equity of their public service provision (and the fees, taxes or other obligations imposed to citizens), assessing not only its rules for accessing public services but also the social conditions of their potential beneficiaries. For that, it is useful to perform some segmentation analysis of the population, identifying special needs and disadvantaged situations and compare it with the real beneficiaries of their activities and their public services [18].

Sometimes equity is used as a synonym of integrity. GAIT distinguishes between equity and integrity. Integrity refers 
to fair and moral behavior of public authorities and civil servants, and the procedures and institutional agreements to achieve ethical behavior.

Equity refers to objective rules promoting equal opportunities and results. In fact, it is possible that in a public organization, even though all public authorities and civil servants behave morally (integrity), equity might not be achieved, due to differences in society and failures in policy design. Of course, integrity is a necessary condition for equity. If public authorities act based on favoritism, nepotism or discrimination, equity will not be achieved, despite the existing equity rules [17];[18].

\subsubsection{Effectiveness}

Effectiveness can be defined as the ability of a public organization to achieve its goals and objectives and to accomplish its overall mission. Effectiveness is a key element of governance. Public organizations only exist in order to accomplish a mission related to collective or social good. Thus, if a public organization is not able to deliver what is intended to deliver (according to its legal mission) then it is not useful to society [19].

There is not a simple recipe to achieve effectiveness in the public sector, as it depends on the nature of goals and objectives (which may differ greatly for different public organizations). Nevertheless, there is a set of generally accepted principles, actions and institutional agreements that may contribute to enhance effectiveness. These principles and tools have been developed mainly by the New Public Management (NPM), especially by the TQM literature, and by the literature on evaluation of public policies. Briefly (and not exhaustively) describe some of these commonly accepted tools for public organizations to enhance effectiveness [6].

Effective governance affects the entire organizational cycle: strategic planning, resource utilization, value creation, accountability, and assurance. Such a holistic approach ensures that governance is not "bolt on" but "built in"integrated into all aspects of an organization. Moreover, Successful organizations benchmark governance procedures and practices against their peers. They regularly evaluate results to ensure the continuing effectiveness of their governance practices, and adapt and improve them for future opportunities and threats as the organizations and their environments change [4].

\subsubsection{Efficiency}

Efficiency consists on the capability to achieve the desired goals using the minimum possible amount of resources. Efficiency is usually defined by a ratio between goals achieved and resources used. As it is difficult to measure goal achievement, sometimes the ratio between outputs and resources is used [6].
Efficiency should not be confused with effectiveness. Effectiveness is a necessary condition for efficiency. If a public organization does not achieve its intended goals (e.g. it is not effective), it will not be efficient, disregarding how little resources it employs. Efficiency is intrinsically a relative concept. The only way to assess efficiency is tocompare an organization with past data of the same organization and/or with present or past data of similar organizations [16].

In public organizations measurement efficiency is not a simple task, as most services provided by the public organization do not have a market value. Moreover, the characteristics of most public services (inseparable, intangible, simultaneous, uniqueness, etc.) make difficult to evaluate numerically the efficiency of public sector departments. Nevertheless, in order to improve good governance, public organizations should engage in a path of continuous improvement of their efficiency levels. Efficiency should be pursued in all phases of the policy cycle [6].

\subsubsection{Sustainability}

Sustainability is in the capacity to endure over time. According to the UN resolution [14], "Transforming our world: the 2030 Agenda for Sustainable Development", sustainability has three key and indivisible dimensions: economic, social an environmental. For a public organization, sustainability reflects the necessity to consider the social, economic and environmental impact of their policies. This implies that public organizations should take a long-term perspective while deciding, designing and evaluating public policies, taking into account the interests of future generations [6].

In order to achieve sustainability, public organizations should be able to adapt to change in the social, economic and environmental conditions, learn and innovate, and make a proper balance between short, medium and long-term interests, reporting transparently the potential trade-offs between them. This is the reason why sustainability is highly related with risk management [11].

Organizations strive to be competitive and sustainable over the long term; core elements of this are creating and optimizing organizational success and stakeholder value, effective resource utilization, and accountability. Governance should, therefore, be more than a compliance exercise designed with the sole purpose of satisfying regulatory requirements - it should involve both compliance and performance [4].

The following figure 1 summarizes the nine principles and the twelve dimensions that should be used in governance assessment: 


\begin{tabular}{|c|c|c|c|c|c|c|c|c|c|c|c|c|}
\hline & $\begin{array}{c}1 . \\
\text { Legislation } \\
\text { \& Basic } \\
\text { Regulation }\end{array}$ & $\begin{array}{c}2 \\
\text { Organizatio } \\
\text { nal } \\
\text { Structure }\end{array}$ & $\begin{array}{c}3 . \\
\text { Leadership }\end{array}$ & 4. Strategy & $\begin{array}{l}\text { 5. HR } \\
\text { Manageme } \\
\text { nt }\end{array}$ & $\begin{array}{l}\text { 6. Financial } \\
\text { Manageme } \\
\text { nt }\end{array}$ & $\begin{array}{l}\text { 7. Alliances } \\
\text { \& Other } \\
\text { Resources }\end{array}$ & $\begin{array}{c}8 . \\
\text { Processess }\end{array}$ & $\begin{array}{l}\text { 9. HR } \\
\text { Results }\end{array}$ & $\begin{array}{c}10 . \\
\text { Financial } \\
\text { Results }\end{array}$ & $\begin{array}{l}\text { 11. User \& } \\
\text { Output } \\
\text { Results }\end{array}$ & $\begin{array}{l}\text { 12. Social } \\
\text { Impact }\end{array}$ \\
\hline 1. Rule of law & & & & & & & & & & & & \\
\hline 2.Transparency & & & & & & & & & & & & \\
\hline 3.Actountability & & & & & & & & & & & & \\
\hline 4.Participution & & & & & & & & & & & & \\
\hline 5.Integrity & & & & & & & & & & & & \\
\hline 6.Fquity & & & & & & & & & & & & \\
\hline T.Effectiviness & & & & & & & & & & & & \\
\hline 8.efficiency & & & & & & & & & & & & \\
\hline 9. Sustainability & & & & & & & & & & & & \\
\hline
\end{tabular}

Fig 1: GAIT model structure [7]

In figure 2 , it demonstrates how the GAIT model can be used horizontally and vertically.

\begin{tabular}{|c|c|c|c|c|c|c|c|c|c|c|c|c|}
\hline & $\begin{array}{c}1 . \\
\text { Legislation } \\
\text { \& Basic } \\
\text { Regulation }\end{array}$ & $\begin{array}{c}2 . \\
\text { Organizatio } \\
\text { nal } \\
\text { Structure }\end{array}$ & $\begin{array}{c}3 . \\
\text { Leadership }\end{array}$ & 4. Strategy & $\begin{array}{c}\text { 5. HR } \\
\text { Manageme } \\
\text { nt }\end{array}$ & $\begin{array}{c}\text { 6. Financial } \\
\text { Managense } \\
\text { nt }\end{array}$ & $\begin{array}{l}\text { 7. Allances } \\
\text { \& Other } \\
\text { Rescarces }\end{array}$ & $\begin{array}{c}\text { 8. } \\
\text { Processess }\end{array}$ & $\begin{array}{l}\text { 9. HR } \\
\text { Resuits }\end{array}$ & $\begin{array}{c}10 . \\
\text { Financial } \\
\text { Results }\end{array}$ & $\begin{array}{c}\text { 11. User } 8 \\
\text { Output } \\
\text { Results }\end{array}$ & $\begin{array}{l}\text { 12. Social } \\
\text { Impact }\end{array}$ \\
\hline 1.Rule of taw & & & & & & & & & & & & \\
\hline 2.Transparency & & & & & & & & & & & & \\
\hline 3.Accountability & & & & & & & & & & & & \\
\hline 4.Participation & & & & & & & & & & & & \\
\hline s.integrity & & & & & & & & & & & & \\
\hline 6Equity & & & & & & & & & & & & \\
\hline 7.Effectiviness & & & & & & & & & & & & \\
\hline 8.EHliciency & & & & & & & & & & & & \\
\hline 9.Sustainability & & & & & & & & & & & & \\
\hline
\end{tabular}

Fig 2: The mechanism of GAIT model [7] 
As it's demonstrated from figure2, the application of governance assessment can be done horizontally or vertically, which means the public organization can start its governance assessment starting from rule of law principle, and then apply it on the twelve dimensions and so on. In contrast, they can start in governance assessment vertically by starting from legislation dimension and regulation and apply it on the ninth principles and so on.

\subsection{The Relationship between Accountable}

\section{Governance and Governance Assessment Principles}

Accountable governance refers to the collective responsibility of officials to preserve the public's trust in government by delivering on policy outcomes and safeguarding taxpayer funds. Accountable governance involves systems and coordinated actions through which the public sector ensures the effectiveness, efficiency and economy of public expenditure. It relies on tools that promote value-for-money, integrity and transparency in government, such as external control, internal control, sanctions, and enforcement. These tools create an enabling environment for greater accountability and improved governance [20].

Accountable governance is not the responsibility of one institution, but many entities and individuals across all branches of government - the legislature, the judiciary and the executive. This includes supreme audit institutions (SAIs), internal control bodies, the Centre of Government, line ministries, law enforcement, and prosecutorial bodies, to name a few [20].

Professional accountants in organizations are typically involved in planning, implementing, executing, evaluating, and improving governance in their organizations. Similarly, many organizations seek advice from their accounting firm on how to improve their governance. In addition, many professional accountants in organizations have a responsibility to provide objective and accurate information and analyses to support these activities, as well as overall responsibility in governance areas, such as external business reporting. These factors put professional accountants in an excellent position to ensure that governance is integrated throughout an organization [4].

Effective internal control processes and independent external audit institutions are critical to making sure that governments are operating in an optimal way, without waste or fraud, to deliver the policies and programs that benefit citizens [20].

The public interest objective outlined in IFAC's mission statement encompasses both public and private sectors. Companies influence the strength of an economy and the governmental organizations as well. Given the size of the public sector internationally, poor financial management results in a huge economic cost to the world's economy, and that really is important. Moreover, while there is certainly public interest issues associated with the transparent reporting of information on a company's performance, it would argue that there is an even stronger public interest argument for demanding transparent financial reporting from governments [21].

Ball [21] highlighted the recurring theme of restoring public confidence in financial reporting and financial markets. In order to consider the extent to which can have confidence in governmental financial reporting. Before doing that, it is appropriate to remind of the reasons that should expect high quality reporting from governments, which are reflected in three reasons:

First: Performance: Governments internationally shift billions, trillions, of dollars from the private sector to the public sector, with the objective of improving the well-being of the society and economy. If governments do not operate in an efficient and effective manner, or invest wisely, this represents a huge drain on an economy. Governments, just like companies, need timely and accurate financial information to monitor and manage their performance.

Second: Accountability: Governments are not spending their own money. They are spending people's money. They are entrusted with the management of assets and liabilities that have been built up over decades and which will have an impact on the welfare of citizens for many more decades. Taxpayers and citizens are entitled to information which allows then to hold governments accountable for their use of public resources, including the extent to which current revenues are sufficient to pay for the services provided, and whether balance sheets are strong enough to withstand external shocks, not to mention meeting their current obligations associated with long-term trends like an aging population.

Third: Representative government: A government, regardless of the form it takes, represents the interests of the people it governs. Good government requires that constituents have confidence in those that govern. This confidence is enhanced when governments fully inform their constituents, and provide them with reliable financial information. Transparent financial reporting is one means by which governments can engage constituents in the political process and engender confidence.

\section{FINDINGS}

After the highlighting on the Governance assessment as an improvement tool and accountable governance, findings can be summarized as the following:

Governance assessment is a tool focuses on providing guidance and reporting inspired by integrated reporting movement in the private sector. 
Governance assessment Allow public organizations to engage either in a complete systematic assessment of their governance, or to take a first partial approach. Moreover it aims to incentive public organizations to engage in a continuous improvement of good governance path, allowing them to identify strengths and weakness and to benchmark with best practices.

Professional accountants in public organizations are typically involved in planning, implementing, executing, evaluating, and improving governance in their organizations. Similarly, many organizations seek advice from their accounting firm on how to improve their governance.

There are at least three key reasons that should be reflected on the high quality of governmental financial reporting: performance, accountability and representative government.

\section{CONCLUSION}

It is very clear that the concept of corporate governance moved from private sector to public sector with new definition which is "Good governance". Both concepts have some of similarities in some principles especially with these related to transparency, accountability, integrity. As the nature of public organizations is totally different regarding to its structure, there are other terms that are not used in private sector such as rule of law, legislations and basic regulations, and social impact. The application of good governance and accountable governance in Jordanian public organizations is the first step to get transparent managerial and financial reports; even there are a lot of obstacles that may prevent the quick progress in the application of GAIT and accountable governance such as:

- There is not enough staff who can apply/assess the GAIT model to ensure that the Good governance is available and satisfied public organizations.

- Difficulty in the application GAIT model as whole with its nine principles and twelfth dimensions. Therefore, public organizations can apply/assess certain principle/s on the twelfth dimensions, until they get enough experience in governance assessment.

- Evaluators/assessors must have very good knowledge and solid background in different areas in public organizations such as human resources, Accounting and law.

- Governance assessment and accountable governance needs qualified assessors in those dimensions related to financial management and financial results, to ensure that there are no manipulations in financial and managerial reports, in order to protect public organizations and increase public trust towards their organizations.

\section{REFERENCES}

[1] MoPSD. (2016). Good governance in Jordan. Amman: MoPSD
[2] Lægreid , P., \&Verhoest, K. (2010). Governance of Public Sector Organizations: Proliferation, Autonomy and Performance. Palgrave Macmillan

[3] OECD. (2010). Implementing a Code of Conduct for the Public Sector in Jordan

[4] IFAC. (2017). International Federation of Accountants. Retrieved 2017, from https://www.ifac.org/

[5] CAF. (2013). Governance in public sector

[6] OECD. (2015). G20/OECD Principles. Paris: OECD Publishing.

[7] SIGMA. (2016). Good Governance. European Union

[8] MoPSD. (2014). Retrieved 9 15, 2017

[9] Korosteleva, E., \&Bosse, G. (2009). Changing Belarus? The Limits of EU Governance in Eastern Europe, Conflict and Cooperation. 44(2), 65-143

[10] MoPSD; SIGMA. (2016). User Guide: Governance assessment. Amman: Ministry of Public Sector Development

[11] MoPSD. (2014). Good governance for public sector development. AMMAN: MoPSD

[12] IFAC. (2015). International accounting standards for public sector organizations. International Federation of accountants

[13] International Institute of Chartered Secretaries and Administrators. (2013). Principles of Corporate Governance for Charities

[14] UN. (2014). United Nations Economic and Social Commission for Asia and the Pacific

[15] Bovens, M. (2007). Problems of Democratic Accountability in Network and Multilevel Governance. European Law Journal, 13(4), 447-468

[16] Fung, A. (2006). Varieties of Participation in Complex Governance. Public Administration Review, 66, 66-75

[17] Killinger, B. (2010). Doing the Right Thing for the Right Reason. McGill-Queen's Press

[18] Rice, M. (2004). Organizational Culture, Social Equity, and Diversity. Journal of Public affairs, 10(2), 143-154

[19] Mihaiu, D., Opreana , A., \&Cristisco, M. (2010). Efficiency, Effectiveness and Performance of the public sector. Journal of economic forecasting, 132147

[20] OECD. (2017). Retrieved 2017, from http://www.oecd.org

[21] Ball, I. (2006). Role of IFAC in Restoring Public Confidence in the Accounting Profession. Institute of Chartered Accountants of Pakistan.

\section{BIOGRAPHIES}

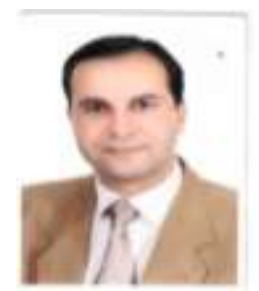

Hasan Mansurwas born in Irbid, Jordan 1976. Mansur is a $\mathrm{PhD}$ Candidate at doctoral school of management and business administration at SzentIstvan University, Godollo, Hungary. He is Head of Institutional Support at 
Ministry of Public Sector Development. Moreover, he is Senior Lecturer and Trainer at Institute of Banking Studies Central Bank of Jordan. Mr. Mansur is a certified assessor at European Foundation Quality Management (EFQM Assessor).

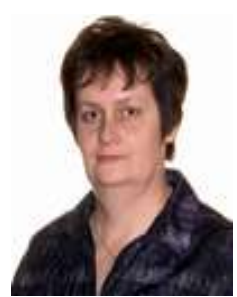

Anita Tangl, Associate Professor at SzentIstvan University Godollo, Hungary 